\title{
Click grafting of seaweed bioactive polysaccharides onto PVC surfaces using ionic liquid as green solvent and catalyst
}

\author{
Sandra Bigot ${ }^{\mathrm{a}}$, Guy Louarn ${ }^{\mathrm{b}}$, Nasreddine Kébir*a ${ }^{* a}$ and Fabrice Burel $^{\mathrm{a}}$ \\ ${ }^{a}$ Normandie Université, INSA de Rouen, CNRS UMR 6270 FR 3038, Avenue de l'université BP08, 76801 \\ Saint-Etienne du Rouvray, France \\ ${ }^{b}$ Institut des Matériaux Jean Rouxel (IMN), UMR 6502, CNRS-Université de Nantes, 2 rue de la Houssinière, \\ BP 32229, 44322 Nantes, France
}

A green and click approach of grafting polysaccharides onto PVC surfaces was developed. PVC isothiocyanate surfaces (PVC-NCS) were prepared by nucleofilic substitution of the chloride groups by isothiocyanate groups in DMSO/water medium. Unmodified seaweed antibacterial polysaccharides were then directly grafted onto the PVC-NCS surface using ionic liquid as solvent and catalyst. The new grafted PVC surfaces were well characterized by AFM, XPS, contact angle measurements.

Keywords: PVC, ionic liquid, polysaccharides, click chemistry. 


\section{Introduction}

In the context of the world ecological and economical crisis, the development of new straightforward and green chemistry process is of great interest.

During the last decade, room temperature ionic liquids (ILs) had known a great development as media and catalysts for organic reactions ${ }^{1-6}$. Their recyclable characteristics and their catalytic activities make them a green alternative to organic solvents. Moreover, ILs exhibit many others attributes like chemical-thermal stability and ability to solvate a broad range of inorganic and organic compounds.

Polysaccharides are one of the most important reactive and active biopolymers. They have many applications in the medical field. In particular, heparin and chitosan, were grafted onto biomaterial surfaces in order to improve biocompatibility and/or to prevent bacteria, blood platelets or protein attachment. Often, the grafting strategies were multi-step ones, including uncontrolled surface physical treatments or multi-step chemical modifications of the surface and/or of the polymer ${ }^{7}$.

Poly(vinylchloride) (PVC) represents $25 \%$ of plastics used in medical applications ${ }^{8}$. It is widely used as biomaterial. However, as far as we know, only few examples of grafting of polysaccharides onto PVC surfaces were described in the literature ${ }^{9-10}$. Actually, C. Mao et $a l^{9}$ grafted $O$-butyrylchitosan (OBCS) onto PVC surface. OBCS was previously bound to 4-azidobenzoic acid and then it was covalently immobilized onto PVC surfaces by ultraviolet irradiations. Besides, Asadinezhad et $a l^{10}$ functionalized PVC surface by plasma treatment in air radical and graft copolymerization of acrylic acid through grafting from pathway. Then, chitosan monolayer was bound onto surfaces. Z. Zhou et al ${ }^{11}$ grafted heparin onto aminated PVC after modification of the polysaccharide chains with N-hydroxysuccinimide, using 1-ethyl-3-(3-dimethylaminopropyl)carbodiimide as coupling agent.

Recent studies have reported the dissolution and chemical modification of polysaccharides, especially cellulose, in ILs such as N,N'-diimidazolium chloride salts ${ }^{12}$, N,N'-diimidazolium formate, phosphate or phosphonate ${ }^{13-14}$ and 1-butyl-3-methylimidazolium chloride ${ }^{15}$. Indeed, because of high degree of intra-molecular hydrogen bonds, cellulose exhibit a high crystallinity, this makes difficult its dissolution in common organic solvents. ILs cleave these hydrogen bonds by their ionic interaction and consequently, they dissolve the polymer ${ }^{16}$.

Moreover, it has been reported that some seaweed polysaccharides such as alginates, carrageenan, aragose and fucans ${ }^{17-21}$ exhibited biological properties in good correlation with their chemical structures. Especially, sulfated polysaccharides from algae possess important pharmacological activities such as anticoagulant, antioxidant, antiproliferative, antitumoral, anticomplementary, anti-inflammatory, antiviral, antipeptic and antiadhesive activities ${ }^{21-24}$.

In this work, we describe a green and click chemical process of grafting bioactive seaweed polysaccharides as well as methylcellulose, a strong bacteria and protein repellent polymer ${ }^{25}$, onto PVC surfaces. A first step consisted on displacement of chloride groups within the PVC surface by isothiocyanate groups, in water/DMSO mixture, to afford PVC-NCS surfaces. Then, unmodified polysaccharides were directly grafted onto these surfaces using $[\mathrm{C} 2 \mathrm{mim}]\left[(\mathrm{MeO})(\mathrm{H}) \mathrm{PO}_{2}\right]$ ionic liquid as green solvent and catalyst (Scheme 1). 


\section{Experimental}

Commercial bulk polymerized PVC was obtained from Sigma-Aldrich, Lyon, France. The average molecular weights determined by GPC were $\overline{\mathrm{M}_{\mathrm{w}}}=80000 \mathrm{~g} / \mathrm{mol}$ and $\overline{\mathrm{M}_{\mathrm{n}}}=47000$ $\mathrm{g} / \mathrm{mol}$. Seaweed polysaccharides were provided from the CEVA (www.ceva.fr), Paimpol, France. Their characteristics are depicted in Table 1. Methylcellulose $\left(\overline{\mathrm{M}_{\mathrm{w}}}=88000 \mathrm{~g} / \mathrm{mol}\right.$, degree of methylation $(\mathrm{DM})=1.5-1.9)$, tetrabutylammonium hydroxide $(\mathrm{TBAH})(40 \mathrm{wt} \% \mathrm{in}$ water) and N-ethylimidazole $(\geq 95 \%)$ were purchased from Sigma-Aldrich. Potassium thiocyanate (KSCN) was purchased from Merck, and dimethylphosphite (98\%) from Alfa Aesar.

\section{Characterizations}

NMR spectra were recorded on a Bruker Avance (300MHz) Spectrometer. IR spectra were recorded on a FTIR (Perkin-Elmer) equipped with a diamond ATR device (Attenuated Total Reflection).

XPS measurements were carried out at room temperature. An Axis Nova instrument from Kratos Analytical spectrometer with $\mathrm{Al} \mathrm{K} \alpha$ line $(1486.6 \mathrm{eV})$ as excitation source has been used. The core level spectra were acquired with an energy step of $0.1 \mathrm{eV}$ and using a constant pass energy mode of $20 \mathrm{eV}$, to obtain data in a reasonable experimental time (energy resolution of $0.4 \mathrm{eV}$ ).

The pressure in the analysis chamber was maintained lower than 10-7 Pa. The background spectra are considered as Shirley type and curve fitting is carried on with a mixture of Gaussian-Lorentzian functions [A.K. Berreshein, M. Mattern-Klosson, W. Fresenius, J. Anal. Chem. 341 (1991) 121]. The error in defining the position of peaks is estimated at about 0.1 $\mathrm{eV}$. No surface cleaning, using Ar sputtering for example was made. We know from experience that carbonaceous atmospheric contamination on material usually occurs, but in our case, ion sputtering can be suspected of changing chemical composition and inducing structural damage.

Surface energy of the materials were evaluated using Digidrop Goniometer (GBX, France), by static contact angle $\left(\theta_{\mathrm{i}}\right)$ measurements on the sample surfaces with 3 liquids: water, diiodomethane and glycerol. The static contact angles were measured at the equilibrium time. At least five measurements on different surfaces were performed to calculate the mean contact angle and its standard deviation. According to the Owens-Wendt relationship (1) the dispersive $\gamma_{s}^{d}$ and polar $\gamma_{s}^{p}$ components of the surface energies $\left(\gamma_{s}=\gamma_{s}^{d}+\gamma_{s}^{p}\right)$ of the samples were determined.

$$
\text { (1) } \frac{\left(1+\cos \theta_{i}\right) \gamma_{i}}{2 \sqrt{\gamma_{i}^{d}}}=\sqrt{\gamma_{s}^{p}} \times \sqrt{\frac{\gamma_{i}^{p}}{\gamma_{i}^{d}}}+\sqrt{\gamma_{s}^{d}}
$$

Where $\gamma_{i}, \gamma_{i}{ }^{d}, \gamma_{i}^{p}$ are the solvent superficial tension parameters.

Surface polarities $(\mathrm{P})$ of the materials are calculated using equation (2):

(2) $\mathrm{P}=\frac{\gamma_{\mathrm{s}}^{\mathrm{p}}}{\gamma_{\mathrm{s}}} \times 100$

Dynamic contact angle measurements with water were also performed to get the Advancing Angle (AA) and the Receding Angle (RA) as well as the surface hysteresis (Hys=AA-RA).

An AFM microscope (JPK instruments, NanoWizard, Berlin, Germany) was used for imaging and roughness measurements. AFM images were obtained by using the intermittent contact mode AFM in air. Classical silicon cantilevers were used (NanoWorld Pointprobe ${ }^{\circledR}$ NCHR). The average force constant and resonance were approximately $42 \mathrm{~N} . \mathrm{m}^{-1}$ and $320 \mathrm{kHz}$, 
respectively.Topographic images were taken at different locations on the surface, in order to account for any heterogeneity in the coverage of the polysaccharides. AFM data were analyzed by the software SPM Image Processing v.3 from JPK Instruments, to extract the surface roughness (calculated on a $10 \mu \mathrm{m}^{2}$ area).

\section{Preparation of PVC films}

About $1 \mathrm{~g}$ of PVC powder was dissolved in $40 \mathrm{~mL}$ of dichloromethane and poured into a Teflon mould. PVC films were then obtained by slow solvent evaporation under nitrogen atmosphere.

\section{Preparation of PVC- isothiocyanate surfaces (PVC-NCS)}

In a round bottom flask, $\mathrm{KSCN}\left(9.0 \times 10^{-2} \mathrm{~mol}\right)$ and tetrabutylammonium hydroxide (TBAH) $\left(4.5 \times 10^{-2} \mathrm{~mol}\right)$ were dissolved in a $60 \mathrm{~mL}$ of DMSO/water $(4 / 1)$ mixture. PVC sheets $(1 \mathrm{x} 1$ $\mathrm{cm}^{2}$ ) were immersed and the medium was heated at $60^{\circ} \mathrm{C}$ for $17 \mathrm{~h}$ under slow-stirring. Then, the PVC sheets were thoroughly washed with water, rinsed with diethyl ether and dried at $60^{\circ} \mathrm{C}$. The same reaction mixture could be recycled 4 to 5 times.

FTIR: $v_{\max } / \mathrm{cm}^{-1} 2150(\mathrm{~S}-\mathrm{CN}), 2051(\mathrm{~N}=\mathrm{C}=\mathrm{S}), 1600(\mathrm{C}=\mathrm{C})$.

\section{Synthesis of 1-ethylimidazolium phosphate ([C2mim] $\left.\left[(\mathrm{MeO})(\mathrm{H}) \mathrm{PO}_{2}\right]\right)$}

The ionic liquid, i.e. 1-ethylimidazolium phosphate, was prepared as described in the literature [5]. Briefly, in a round bottom flask containing $225 \mathrm{~mL}$ of THF, $N$-ethylimidazole (622 mmol) and dimethyl phosphite $(622 \mathrm{mmol})$ were added dropwise under nitrogen atmosphere at room temperature. Then, the mixture was stirred at $90^{\circ} \mathrm{C}$ for 2 days. Then, a biphasic system was obtained. The lower phase containing the IL was separated from the upper phase (THF) and washed with diethyl ether. The obtained ionic liquid (IL) was dissolved in dichloromethane, purified on neutral activated alumina and then dried under vacuum.

${ }^{1} \mathrm{H}$ NMR $\left(300 \mathrm{MHz}, \mathrm{CDCl}_{3}, \delta \mathrm{ppm}\right) 1.58\left(\mathrm{t}, 3 \mathrm{H}, \mathrm{J}=7.4 \mathrm{~Hz}, \mathrm{NCH}_{2} \mathrm{CH}_{3}\right), 3.44(\mathrm{~d}, 3 \mathrm{H}, \mathrm{J}=11.8$ $\left.\mathrm{Hz}, \mathrm{POCH}_{3}\right), 4.01\left(\mathrm{~s}, 3 \mathrm{H}, \mathrm{NCH}_{3}\right), 4.32\left(\mathrm{q}, 2 \mathrm{H}, \mathrm{J}=7.4 \mathrm{~Hz}, \mathrm{NCH}_{2} \mathrm{CH}_{3}\right), 6.96(\mathrm{~d}, 1 \mathrm{H}, \mathrm{J}=5.41$ $\mathrm{Hz}, \mathrm{PH}), 7.32(\mathrm{~d}, 2 \mathrm{H}, \mathrm{J}=11.4 \mathrm{~Hz}, \mathrm{NCHCHN}), 10.40(\mathrm{~s}, 1 \mathrm{H}, \mathrm{NCHN}) .{ }^{13} \mathrm{C}$ NMR $(75 \mathrm{MHz}$, $\mathrm{CDCl}_{3}, \delta$ ppm) $15.8,36.7,45.5,50.7,121.7,123.6,139.3$.

\section{Grafting of polysaccharides onto PVC-NCS surfaces}

Each polysaccharide was dissolved in the ionic liquid $(\mathrm{C}=1 \mathrm{mg} / \mathrm{mL})$ under appropriate conditions (Table 1). Then, the PVC-NCS sheets were added to these solutions at $60^{\circ} \mathrm{C}$. After stirring for $24 \mathrm{~h}$, the PVC sheets were thoroughly washed with water, rinsed with diethyl ether and dried at $60^{\circ} \mathrm{C}$.

The Ionic liquid was recycled by dialysis in water. The polysaccharides were retained in the dialysis tube and the IL migrated outside the tube. Then, the IL was dried under vacuum. 


\section{Results and discussion}

Scheme 1

The chemical grafting of polysaccharide onto PVC surfaces was performed in two steps (Scheme 1). In a first step, chloride groups of PVC surface were substituted by isothiocyanate groups (-NCS) via a reaction with $\mathrm{KSCN}$, in presence of TBAH as phase transfer catalyst ${ }^{26}$ and DMSO/water (4/1) as solvent. The isothiocyanate groups resulted from isomerisation of thiocyanate ions. Nevertheless, Kameda et al. reported that phase transfer agents, such as TBAH, favored the substitution $\left(\mathrm{SN}_{2}\right)$ over the elimination of $\mathrm{HCl}^{27}$.

FTIR spectra of the treated surfaces (PVC-NCS) showed a characteristic band of isothiocyanate groups at $\sim 2050 \mathrm{~cm}^{-1}$. However, two bands at $\sim 2150 \mathrm{~cm}^{-1}$ and at $\sim 1600 \mathrm{~cm}^{-1}$ were also observed and were ascribed to thiocyanate groups and to double bonds resulting from the elimination, respectively.

The surface elemental compositions of PVC and PVC-NCS surfaces were determined by XPS analysis. The XPS results are shown in Table 2. The contribution of poly(dimethylsiloxane) (PDMS), used as PVC plasticizer, was removed from the elemental analysis. As expected, XPS survey scans obtained from the PVC surface gave two signals corresponding to $\mathrm{C}$ and $\mathrm{Cl}$ with contributions of $66.6 \%$ and $33.4 \%$, respectively. PVC-NCS surface revealed the presence of $\mathrm{N}(1.5 \%)$ and $\mathrm{S}(1.3 \%)$ suggesting that the thiocyanation reaction was successful. However, the percentage of $\mathrm{Cl}$ decreased dramatically confirming a PVC dechlorination (the elimination) under the operating conditions. The XPS survey scans for the main components were analyzed to assign the peaks $\mathrm{C}_{1 \mathrm{~s}}, \mathrm{~N}_{1 \mathrm{~s}}$ and $\mathrm{S}_{2 \mathrm{p}}$ to chemical functions (Fig.1 and Table 2). The $\mathrm{C}_{1 \mathrm{~s}}$ peak was decomposed into four peaks. The peaks ranging from 284 to $285 \mathrm{eV}$ are ascribed to $\mathrm{C}$ of saturated and unsaturated hydrocarbon chains. The peak at 286.4 $\mathrm{eV}$ is attributed to $\mathrm{C}$ making single bonds with $\mathrm{N}, \mathrm{O}, \mathrm{S}$ or $\mathrm{Cl}$. The contribution of this peak is too weak $(6.2 \%)$ confirming the elimination of $\mathrm{Cl}$ during chemical treatment. The high resolution XPS spectra of the $\mathrm{N}_{1 \mathrm{~s}}$ region revealed three peaks. The peak at $394.8 \mathrm{eV}$ is owing to residual thiocyante ions adsorbed onto the surface. The peak at $399.9 \mathrm{eV}$ is ascribed to grafted isothiocyanate and thiocyante groups. The peak at 401.5 is due to ammonium groups of residual TBAH, which exhibited also a very weak signal at $532.2 \mathrm{eV}$, undetectable in the survey spectra $(<1 \%)$. The high resolution XPS spectra of the $S_{2 p}$ region revealed two peaks; each peak corresponds to two spin-orbit transitions. As usual, the main spin-orbit transition $3 / 2$ was used for quantification. The peak at $136.8 \mathrm{eV}$ is ascribed to the $\mathrm{S}$ in thiocyante groups and residual thiocyante ions. The peak at $168.1 \mathrm{eV}$ is ascribed to the $\mathrm{S}$ in isothiocyante groups.

Static and dynamic contact angle measurements performed on modified and unmodified PVC surfaces are reported in Table 3. In comparison with PVC, the PVC-NCS surface showed a significant decrease of static and dynamic contact angles with water. The AA is characteristic of the wettability of the low-energy or hydrophobic part of the surface whereas the RA is more characteristic of the high-energy or hydrophilic part. The balance between the two parts was reduced as suggested by the decrease of hysteresis value (from 48 to 33\%). This indicated that thiocyanation increased considerably the hydrophilicity of the PVC surface. In addition, the surface polarity increased from 2.3 to $32.7 \%$.

AFM data of the PVC and PVC-NCS surfaces are depicted in Figure 1 and Table 3. One can observe that the surface treatment with NCS led to changes in surface morphology without significant variation in the surface roughness. 
In a second step, seaweed polysaccharides as well as MethylCellulose dissolved in an ionic liquid (IL), i.e. [C2mim][(MeO)(H)PO $\left.\mathrm{PO}_{2}\right]$, were directly grafted onto PVC-NCS surface (Scheme 1).

The IL has been chosen for three reasons:

- It solubilized polysaccharides and not PVC.

- It was a good catalyst for the grafting reaction.

- The reaction could not be performed in the classical polysaccharide solvents such as water or alcohols, because these solvents reacted with NCS. In addition, in these conditions an external catalyst was need.

The seaweed polysaccharides used were laminarin, ulvans, fucans and zosterin. Ulvans and fucans are sulfonated polymers. These polysaccharides contain also a small amount of nitrogen (Table 1) owing to presence of residual proteins coming from their natural media. The conditions of polysaccharide dissolution in IL were optimized and reported in Table 1. After complete dissolution, the PVC-NCS samples were immersed in the polysaccharide solution in IL $(1 \mathrm{mg} / \mathrm{mL})$ during $24 \mathrm{~h}$ at $60^{\circ} \mathrm{C}$, to allow the chemical grafting. Besides, the addition of an external catalyst, namely the dibutyltin dilaurate (DBTL), to the reaction medium did not change the final surface properties (results not shown), which suggests a catalytic effect of the IL. Indeed, it is well known that ammonium salts have catalytic activities in nucleophilic addition reactions, such as the reaction of hydroxyle groups with isocyanate groups ${ }^{28,29}$. The obtained PVC grafted polysaccharide surfaces were thoroughly cleaned before characterizations.

In comparison with the PVC-NCS surfaces, the elemental analysis by XPS of the grafted surfaces showed the presence of $\mathrm{O}$ and the increase of $\mathrm{N}$ percentage, suggesting the presence of polysaccharides and their residual proteins onto the surface. However, the percentages of $S$ being affected by the presence of proteins, the sulfonation degree of some polysaccharides, they varied in an unexpected manner. Furtheremore, the grafting of the Ulvan 816 seemed to be less efficient since it exhibited the lowest percentages of $\mathrm{O}$ and $\mathrm{S}$. This result may be explained by the high molecular weight of this polymer limiting its mobility and reactivity onto the surface.

\section{Table 2}

As a typical example, Figure 1 shows the high resolution XPS spectra of the $C_{1 s}, N_{1 s}$ and $S_{2 p}$ regions for the PVC-NCS surface grafted with Lam812. The $\mathrm{C}_{1 \mathrm{~s}}$ peak was fit with five components. The peaks between 284 and $285 \mathrm{eV}$ arose from hydrocarbon groups $(\mathrm{C}-\mathrm{H}, \mathrm{C}-\mathrm{C})$ and C-Si bond which resulted from the PVC plasticizer (PDMS). The peak at $286.4 \mathrm{eV}$ was assigned to carbons of $\mathrm{C}-\mathrm{Cl}, \mathrm{C}-\mathrm{O}, \mathrm{C}-\mathrm{N}, \mathrm{C}-\mathrm{S}$ bonds as well as $\mathrm{C}-\mathrm{C}-\mathrm{C}$ bonds from polysaccharides rings. This peak contribution varied from 18 to $28 \%$ where about $6 \%$ was due to the surface control (PVC-NCS). The peak at $287.7 \mathrm{eV}$ was ascribed to $\mathrm{C}$ in acetal or hemiacetal functions in polysaccharides. The peak at $288.9 \mathrm{eV}$ was attributed to $\mathrm{C}$ in the thiocarbamate links $(\mathrm{NH}-(\mathrm{C}=\mathrm{S})-\mathrm{O})$, in the carboxylic acid function of some polysaccharides (Ulvans) and proteins, and in the amide function of the residual proteins.

The N1s peak was decomposed into three subpeaks. The peak at $401.5 \mathrm{eV}$ resulted from C- $\mathrm{NH}_{3}{ }^{+}$and $\mathrm{C}-\mathrm{N}^{+}$related to residual proteins and TBAH, respectively. The main peak at $399.9 \mathrm{eV}$ was assigned to the thiocarbamate link and to the thiocyanate and isothiocyanate groups. The contribution of the peak at $384.8 \mathrm{eV}$, corresponding to free thiocyanate ions 
adsorbed onto the surface, was observed only in some grafted surfaces and with a weak contributions.

The $\mathrm{S}_{2 \mathrm{p}}$ high resolution XPS spectra of the grafted surfaces exhibited the same peaks than PVC-NCS surface but with different contributions. The peak at $136.8 \mathrm{eV}$ arose from thiocyanate groups and ions. The peak at $168.1 \mathrm{eV}$ was more intense than the peak at $136.8 \mathrm{eV}$, in the case of surfaces grafted with the seaweed polysaccharides and was ascribed to unreacted isothiocyanate groups, to thiocarbamate functions and to sulfonate groups in some polysaccharides.

PVC-NCS surface grafted with polysaccharides exhibited increased contact angles with water, in comparison with the Ungrafted surfaces. The static contact angles varied in the range of $56^{\circ}$ to $61^{\circ}$, suggesting that these surfaces kept their hydrophilic character. AA with water was very close to static angle, whereas RA was in the range of 15 to $20^{\circ}$. Thus, polysaccharide surfaces exhibited hysteresis in the range of 35 to $47^{\circ}$ which was higher than the one of PVC-NCS. This result is mainly explained by the increase of the hydrophilic-hydrophobic balance after polysaccharide grafting. Besides, hysteresis can also be explained by surface heterogeneity, texture and roughness.

\section{Table 3}

AFM data of the PVC-NCS surface grafted with polysaccharides are also depicted in Table 3. A typical example of AFM height images is given in Figure 1 (PVC-Lam822). These images revealed a modification of surface morphology after polymer grafting. The PVC grafted polysaccharide surfaces exhibited roughness values which were slightly higher than those of the PVC-NCS surface.

\section{Conclusions}

This work showed the possibility of grafting a range of bioactive polysaccharides onto PVC surfaces using a green and straightforward process. This process involved a reaction between alcohol groups of polysaccharides and isothiocyanate groups covalently bounded to PVC surfaces. 1-ethylimidazolium phosphate, an ionic liquid, was used as solvent for polysaccharides and as catalyst for the grafting reaction. This process is expected to be used to graft any specific polymer bearing alcohol, amine or thiol groups onto a surface bearing isothiocyanate groups.

\section{Acknowledgements}

This work was a part of the project "Green Intelligent Material (GIMs)" which belongs to the "Interreg IV France (Channel) - England" European program. Authors thanks the Europe and the "haute Normandie" Region for their financial and logistic supports. 


\section{References}

1. A. Kamimura, T. Okagawa, N. Oyama , T. Otsuka, M.Yoshimoto, Green Chem., 2012, 4, 2816-2820.

2. A. Natrajan, D. Wen, Green Chem., 2011, 13, 913-921.

3. C. Chiappe, G.Imperato, E.Napolitano, D.Pieraccinia, Green Chem., 2004, 6, 33-36.

4. K. Anderson , P. Goodrich , C. Hardacre and D.W. Rooney, Green Chem., 2003, 5, 448453

5. Z.W. Wang, L.S. Wang, Green Chem., 2003, 5, 737-739.

6. C. Imrie, R.T. Elago, C.W. McCleland, N. Williams, Green Chem., 2002, 4, 159-160.

7. J.M. Goddard, J.H. Hotchkiss, Prog. Polym. Sci., 2007, 32, 698-725.

8. J.A. Tickner, T. Schettler, T. Guidotti, M. McCally, M. Rossi, Am. J. Ind. Med., 2001, 39, 100-111.

9. C. Mao, W.B. Zhao, A.P. Zhu, J. Shen, S.C. Lin, Process Biochem., 2004, 39, 1151-1157.

10. A. Asadinezhad, I. Novák, M. Lehocký, F. Bílek, A. Vesel, I. Junkar, P. Sáha, A. Popelka, Molecules, 2010, 15, 1007-1027.

11. Z. Zhou, M.E. Meyerhoff, Biomaterials, 2005, 26, 6506-6517.

12. R.P. Swatloski, S.K. Spear, J.D. Holbrey, R.D. Rogers, J. Am. Chem. Soc., 2002, 124, 4974-4975.

13. Y. Fukuya, A. Sugimoto, H. Ohno, Biomacromolecules, 2006, 12, 3295-3297.

14. Y. Fukuya, K. Hayashi, M. Wada, H. Ohno, Green Chem., 2008, 10, 44-46.

15. T. Heinze, K. Schwikal, S. Barthel, Macromol. Biosci., 2005, 5, 520-525.

16. A. Pinkert, K.N. Marsh, S. Pang, Ind. Eng. Chem. Res., 2010, 49 (22), 11121-11130.

17. M. Rinaudo, Polym. Int., 2008, 57, 397-430.

18. J.A. Bohn, J.N. BeMiller, Carbohydr. Polym., 1995, 28, 3-14.

19. M.Y.K. Leung, C. Liu, J.C.M. Koon, K.P. Fung, Immunology Letters, 2006, 105, 101114.

20. I. Wijesekara, R. Pangestuti, S-K. Kim, Carbohydr. Polym., 2011, 84, 14-21.

21. L.S. Costa, G.P. Fidelis, S.L. Cordeiro, R.M. Oliveira, D.A. Sabry, R.B.G. Câmara, L.T.D.B. Nobre, M.S.S.P. Costa, J. Almeida-Lima, E.H.C. Farias, E.L. Leite, H.A.O. Rocha, Biomed. Pharmacother., 2010, 64, 21-28.

22. A. Cumashi, N.A. Ushakova, M.E. Preobrazhenskaya, A. D’Incecco, A. Piccoli, L. Totani, et al. Glycobiology, 2007, 17, 541-552.

23. T.C.G. Azevedo, M.E. Bezerra, M.D. Santos, L.A. Souza, C.T. Marques, N.M. Benevides, et al. Biomed. Pharmacother., 2009, 63, 477-483.

24. E.B. Damonte, M.C. Matulewicz, A.S. Cerezo. Curr. Med. Chem., 2004, 11, 2399-2419.

25. W. Mussard, N. Kebir, I. Kriegel, M. Estève, V. Semetey, Angew. Chem. Int. Ed., 2011, 50,10871-10874.

26. N.R. James, A. Jayakrishnan, Biomaterials, 2003, 24, 2205-2212.

27. T. Kameda, M. Ono, G. Grause, T. Mizoguchi, and T. Yoshioka, Polym. Eng. Sci., 2010, 50, 69-75.

28. JP., pat., 63265910, 1988.

29. N. Kébir, I. Campistron, A. Laguerre, J.F. Pilard, C. Bunel, T. Jouenne, Biomaterials, 2007, 28, 4200-4208. 
Scheme 1. The chemical approach for grafting polysaccharides onto PVC surfaces.

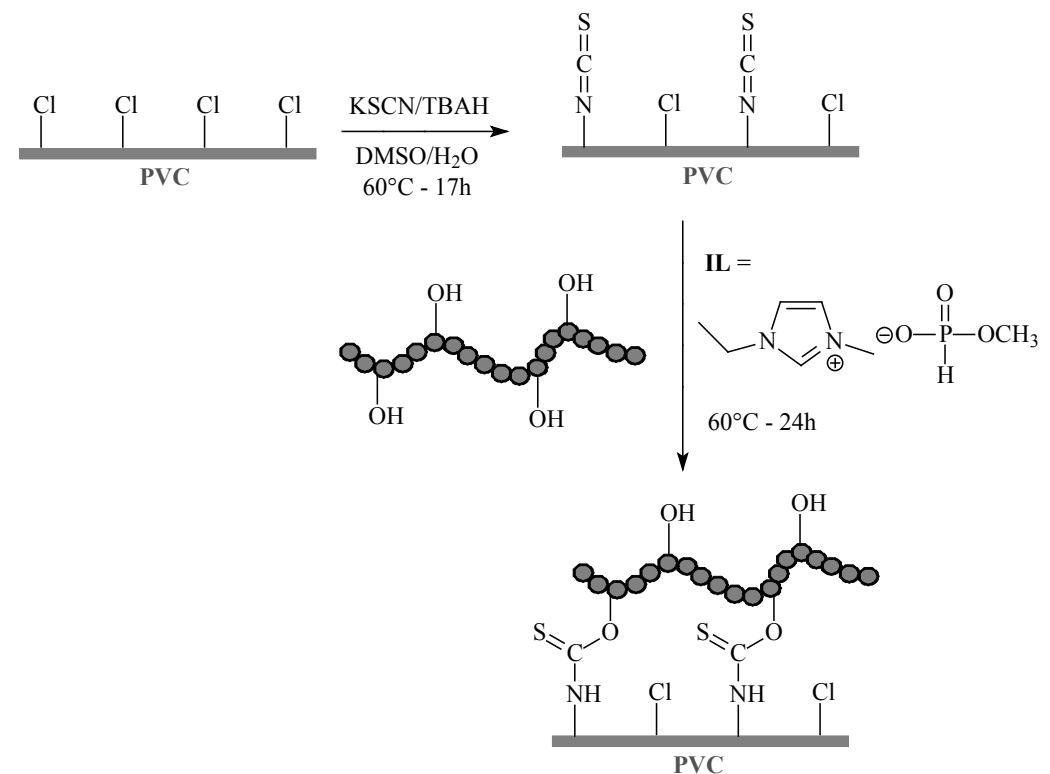


Table 1. Some characteristics of the used seaweed polysaccharides.

\begin{tabular}{|c|c|c|c|c|c|}
\hline Polysaccharide & Seaweed & $\begin{array}{c}\text { Mw } \\
(\mathrm{g} / \mathrm{mol}) *\end{array}$ & $\begin{array}{c}\mathbf{S} \\
(\%) * *\end{array}$ & $\begin{array}{c}\mathbf{N} \\
(\%) * *\end{array}$ & $\begin{array}{c}\text { Conditions of } \\
\text { dissolution in IL } \\
(\mathrm{C}=1 \mathrm{mg} / \mathrm{mL})\end{array}$ \\
\hline Methylcellulose & 1 & 80000 & ND & ND & $60^{\circ} \mathrm{C}(15 \mathrm{~min})$ \\
\hline Laminarin 822 & L. saccharina parmeat & 6990 & ND & ND & $60^{\circ} \mathrm{C}(15 \mathrm{~min})$ \\
\hline Ulvan 901 & U. clathrata & 360000 & 2.2 & 1.6 & $80^{\circ} \mathrm{C}(15 \mathrm{~min})$ \\
\hline Ulvan 815 & U. rotundata & 620300 & 3.14 & 1.2 & $80^{\circ} \mathrm{C}(15 \mathrm{~min})$ \\
\hline Ulvan 816 & U. compressa & 876250 & 2.6 & 1.9 & $80^{\circ} \mathrm{C}(15 \mathrm{~min})$ \\
\hline Fucan 812 & Fucus/Ascophyllum & 438600 & ND & ND & $80^{\circ} \mathrm{C}(15 \mathrm{~min})$ \\
\hline Zosterin 900 & Zosteraceae & 340200 & ND & ND & $\begin{array}{c}95^{\circ} \mathrm{C}(30 \mathrm{~min} \\
\text { under sonication })\end{array}$ \\
\hline
\end{tabular}

* Data supplied by the CEVA: $\overline{\mathrm{M}_{\mathrm{w}}}$ values were determined by High Performance Size Exclusion Chromatography (HP-SEC) using Pullulan calibration curve ranged from 5800 to $1600000 \mathrm{~g} / \mathrm{mol}$.

** Data supplied by the CEVA: N (\%) was determined by the Kjeldhal technique, S (\%) was determined by an internal method (turbidimetry after mineralization). 
Table 2. XPS Data of the prepared surfaces: elemental analysis; peak assignment and contribution.

\begin{tabular}{|c|c|c|c|c|c|c|c|c|c|c|}
\hline $\begin{array}{l}\text { Chemical } \\
\text { State }\end{array}$ & $\begin{array}{c}\text { Binding } \\
\text { Energy } \\
(\mathrm{eV}) \\
\end{array}$ & PVC & $\begin{array}{l}\text { PVC- } \\
\text { NCS }\end{array}$ & $\begin{array}{l}\text { PVC- } \\
\text { MeCell }\end{array}$ & $\begin{array}{c}\text { PVC- } \\
\text { Lam822 }\end{array}$ & $\begin{array}{l}\text { PVC- } \\
\text { Ulv901 }\end{array}$ & $\begin{array}{l}\text { PVC- } \\
\text { Ulv815 }\end{array}$ & $\begin{array}{l}\text { PVC- } \\
\text { Ulv816 }\end{array}$ & $\begin{array}{l}\text { PVC- } \\
\text { Fuc812 }\end{array}$ & $\begin{array}{l}\text { PVC- } \\
\text { Zost900 }\end{array}$ \\
\hline$\% \mathrm{C}$ & - & 66.6 & 91.7 & 70.0 & 67.2 & 65.9 & 65.0 & 65.7 & 68.4 & 69.3 \\
\hline $\begin{array}{c}\underline{\mathbf{C}}-(\mathrm{C}, \mathrm{H}, \mathrm{Si}) \\
\underline{\mathbf{C}}=\underline{\mathbf{C}}\end{array}$ & $284-285$ & 52.9 & 80.7 & 61.0 & 71.7 & 70.8 & 65.4 & 58.0 & 69.8 & 63.4 \\
\hline $\begin{array}{c}\underline{\mathbf{C}}-\overline{\mathrm{S}}, \underline{\mathbf{C}}-\mathrm{O} \\
\underline{\mathbf{C}}-\mathrm{N}, \underline{\mathbf{C}}-\mathrm{Cl} \\
\mathrm{C}-\underline{\mathbf{C}}-\mathrm{C} \text { ring }\end{array}$ & 286.4 & 47.1 & 6.2 & 26.1 & 18.9 & 19.5 & 23.2 & 28.1 & 20.1 & 24.5 \\
\hline $\mathrm{O}-\underline{\mathbf{C}}-\mathrm{O}$ & 287.7 & / & I & 6.2 & 4.5 & 4.6 & 5.5 & 6.6 & 4.8 & 5.8 \\
\hline $\begin{array}{c}(\underline{\mathbf{C}}=\mathrm{O})-\mathrm{O}-, \\
(\underline{\mathbf{C}}=\mathrm{O})-\mathrm{NH}, \\
\mathrm{NH}-(\underline{\mathbf{C}}=\mathrm{S})-\mathrm{O}\end{array}$ & 288.9 & / & I & 6.7 & 4.9 & 5.0 & 6.0 & 7.3 & 5.2 & 6.3 \\
\hline$\% 0$ & - & $\mathbf{0}$ & $<1^{*}$ & 11.8 & 17.6 & 16.8 & 20.5 & 5.3 & 16.1 & 11.7 \\
\hline $\begin{array}{c}-(\mathrm{C}=\underline{\mathbf{0}})-\mathrm{NH} \\
(\mathrm{C}=\underline{\mathbf{O}})-\mathrm{O}-\end{array}$ & 531.6 & I & I & 27.9 & 26.2 & 29.6 & 26.0 & 26.5 & 27.5 & 31.0 \\
\hline $\begin{array}{l}\mathrm{C}-\underline{\mathbf{O}}-\mathrm{C} \\
\mathrm{C}-\underline{\mathbf{0}}-\mathrm{H}\end{array}$ & 532.2 & / & 100 & 44.2 & 47.6 & 40.8 & 48.1 & 47.0 & 45.0 & 38.0 \\
\hline$-(\mathrm{C}=\mathrm{O})-\underline{\mathbf{O}}$ & 533.4 & I & / & 27.9 & 26.2 & 29.6 & 26.0 & 26.5 & 27.5 & 31.0 \\
\hline$\% \mathrm{~N}$ & - & $\mathbf{0}$ & 1.5 & 2.1 & 2.4 & 4.8 & 2.8 & 2.4 & 2.5 & 2.1 \\
\hline $\operatorname{SC} \underline{\mathbf{N}}^{-}$ & 394.8 & I & 5.6 & 3.6 & 0.0 & 2.3 & 1.3 & 0.0 & 0.0 & 2.5 \\
\hline $\begin{array}{l}-\underline{\mathbf{N}}=\mathrm{C}=\mathrm{S}, \\
(\mathrm{C}=\mathrm{O}) \underline{\mathbf{N}} \mathrm{H}, \\
-\mathrm{S}-\mathrm{C} \equiv \underline{\mathbf{N}}, \\
(\mathrm{C}=\mathrm{S}) \underline{\mathbf{N}} \mathrm{H}\end{array}$ & 399.9 & / & 74.2 & 37.1 & 55.7 & 76.7 & 53.4 & 56.9 & 61.7 & 67.8 \\
\hline $\mathrm{C}-\underline{\mathbf{N}} \mathrm{H}_{3}{ }^{+}, \mathrm{C}-\underline{\mathbf{N}}^{+}$ & 401.5 & / & 20.2 & 59.3 & 44.3 & 21.1 & 55.3 & 43.1 & 36.3 & 29.7 \\
\hline$\% \mathrm{~S}$ & - & 0 & 1.3 & 1.0 & 2.3 & 1.4 & 2.2 & 0.4 & 1.5 & 1.2 \\
\hline $\begin{array}{c}\mathrm{C}-\underline{\mathbf{S}}-\mathrm{CN}, \\
\underline{\mathbf{S}}^{-} \mathrm{N}^{-}\end{array}$ & 136.8 & / & 52.7 & 56.3 & 33.3 & 32.5 & 40.3 & 41.9 & 35.2 & 48.7 \\
\hline$>\mathrm{C}=\underline{\mathbf{S}},-\underline{-\mathbf{S}} \mathrm{O} 3$ & 168.1 & / & 47.3 & 43.7 & 66.7 & 67.5 & 59.7 & 58.1 & 64.8 & 51.3 \\
\hline$\% \mathrm{Cl}$ & & 33.4 & 5.5 & 14.6 & 6.7 & 8.4 & 6.9 & 25.8 & 10.0 & 14.9 \\
\hline
\end{tabular}

\footnotetext{
* not detected from the XPS survey spectra.
} 
Table 3. Contact angle data and Roughness of the prepared surfaces.

\begin{tabular}{|c|c|c|c|c|c|c|c|c|c|}
\hline \multirow{3}{*}{ Surface } & \multirow{3}{*}{$\begin{array}{c}\text { Static } \\
\boldsymbol{\theta}_{\text {water }}\left({ }^{\circ}\right)\end{array}$} & \multirow{2}{*}{\multicolumn{3}{|c|}{ Dynamic $\theta_{\text {water }}\left({ }^{\circ}\right)$}} & \multirow{3}{*}{$\begin{array}{c}\gamma^{\mathrm{d}} \\
(\mathrm{mN} / \mathbf{m})\end{array}$} & \multirow{3}{*}{$\begin{array}{c}\gamma^{p} \\
(\mathbf{m N} / \mathbf{m})\end{array}$} & \multirow{3}{*}{$\begin{array}{c}\text { Polarity } \\
(\%)\end{array}$} & \multirow{2}{*}{\multicolumn{2}{|c|}{$\begin{array}{c}\text { Roughness } \\
\text { by AFM* } \\
\text { (nm) }\end{array}$}} \\
\hline & & & & & & & & & \\
\hline & & $\mathbf{A A}$ & $\mathbf{R A}$ & Hyst & & & & $\mathrm{Ra}$ & RMS \\
\hline $\begin{array}{c}\text { PVC } \\
\text { (control 1) }\end{array}$ & $89 \pm 5$ & $90 \pm 3$ & $43 \pm 5$ & 48 & 42.2 & $1.0 \pm 0.8$ & 2.3 & 3.0 & 4.5 \\
\hline $\begin{array}{l}\text { PVC-NCS } \\
\text { (control 2) }\end{array}$ & 4 & 4 & $13 \pm 2$ & 3 & 3 & 18 & 3 & 3.4 & 5.1 \\
\hline PVC-MeCell-1 & $63 \pm 4$ & $62 \pm 1$ & $15 \pm 2$ & $47 \pm 2$ & $42.3 \pm 0.1$ & $7.9 \pm 1.6$ & 15.7 & 4.2 & 6.6 \\
\hline PVC-Lam822 & $56 \pm 3$ & $55 \pm 1$ & $20 \pm 1$ & $35 \pm 1$ & $41.1 \pm 0.9$ & $12.1 \pm 1.1$ & $22.7 \pm 1.1$ & 5.2 & 8.7 \\
\hline PVC-Ulv901 & $61 \pm 2$ & $61 \pm 1$ & $17 \pm 1$ & $44 \pm 1$ & $37.5 \pm 1.8$ & $10.7 \pm 0.6$ & $22.1 \pm 0.4$ & 3.7 & 5.2 \\
\hline PVC-Ulv815 & $56 \pm 1$ & $55 \pm 1$ & $16 \pm 1$ & $39 \pm 1$ & $38.9 \pm 0.8$ & $13.9 \pm 0.6$ & $26.3 \pm 0.3$ & 4.4 & 6.7 \\
\hline PVC-Ulv816 & $59 \pm 3$ & $59 \pm 1$ & $17 \pm 2$ & $42 \pm 2$ & $39.0 \pm 0.6$ & $10.5 \pm 1.0$ & $21.2 \pm 1.2$ & 5.6 & 9.2 \\
\hline PVC-Fuc812 & $59 \pm 5$ & $59 \pm 1$ & $16 \pm 1$ & $43 \pm 1$ & $39.4 \pm 0.9$ & $10.5 \pm 2.2$ & $21.0 \pm 3.1$ & 7.8 & 11.2 \\
\hline PVC-Zost900 & $60 \pm 2$ & $59 \pm 1$ & $15 \pm 1$ & $43 \pm 2$ & $40.5 \pm 0.5$ & $9.8 \pm 0.7$ & $19.5 \pm 1.0$ & 6.5 & 10.3 \\
\hline
\end{tabular}

$\boldsymbol{\theta}_{\text {water: }}$ contact angle with water; AA: Advancing Angle; RA: Receding Angle; Hyst: Hysteresis; $\boldsymbol{\gamma}^{\mathrm{d}}$ : Dispersive component of the surface energy; $\gamma^{\mathrm{p}}$ : Polar component of the surface energy.

* Ra: arithmetic roughness, RMS: Mean Square Roughness. 

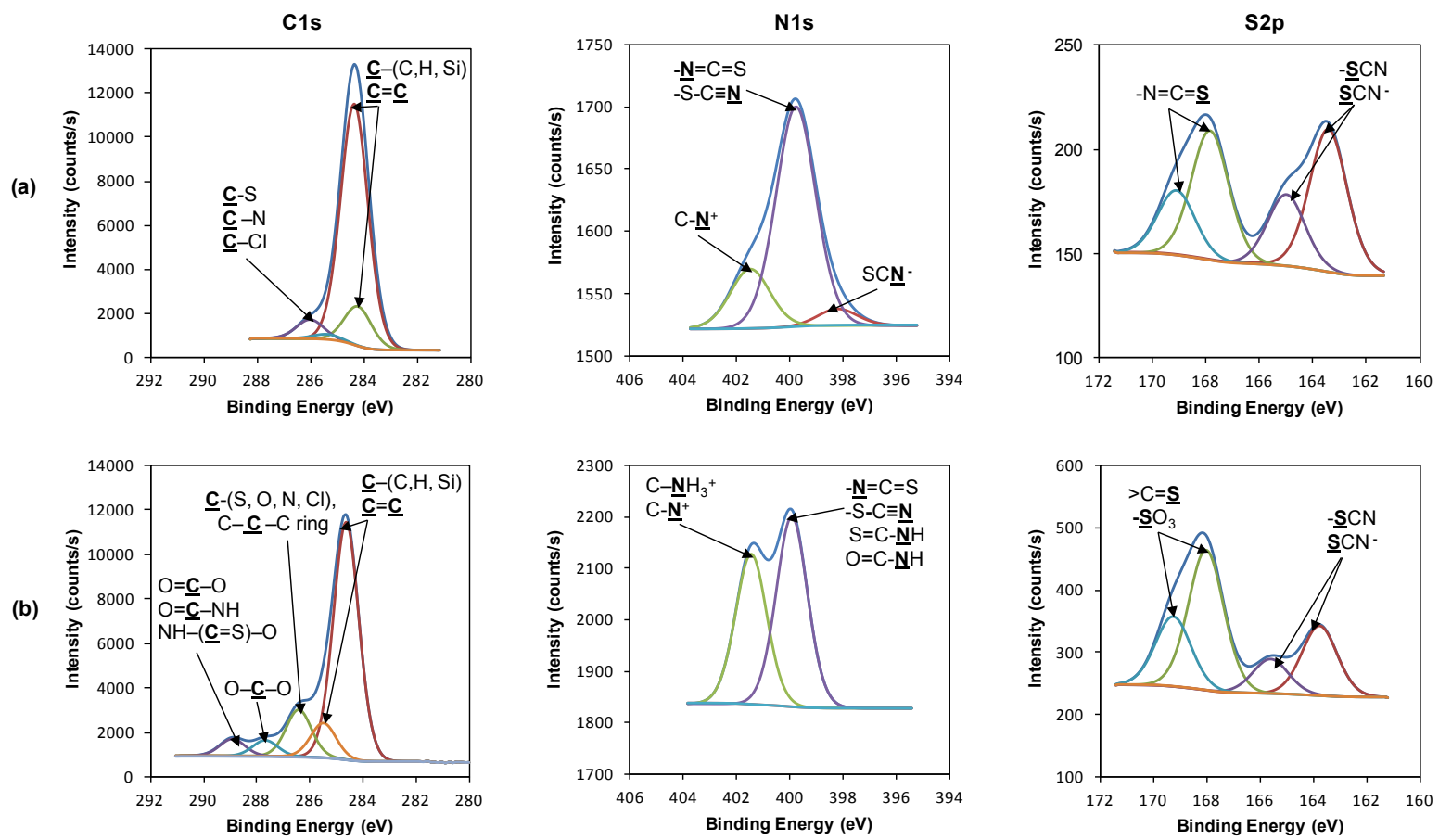

Figure 1. C1s, N1s and S2p high resolution spectra of (a) PVC-NCS and (b) PVC-Lam822. 

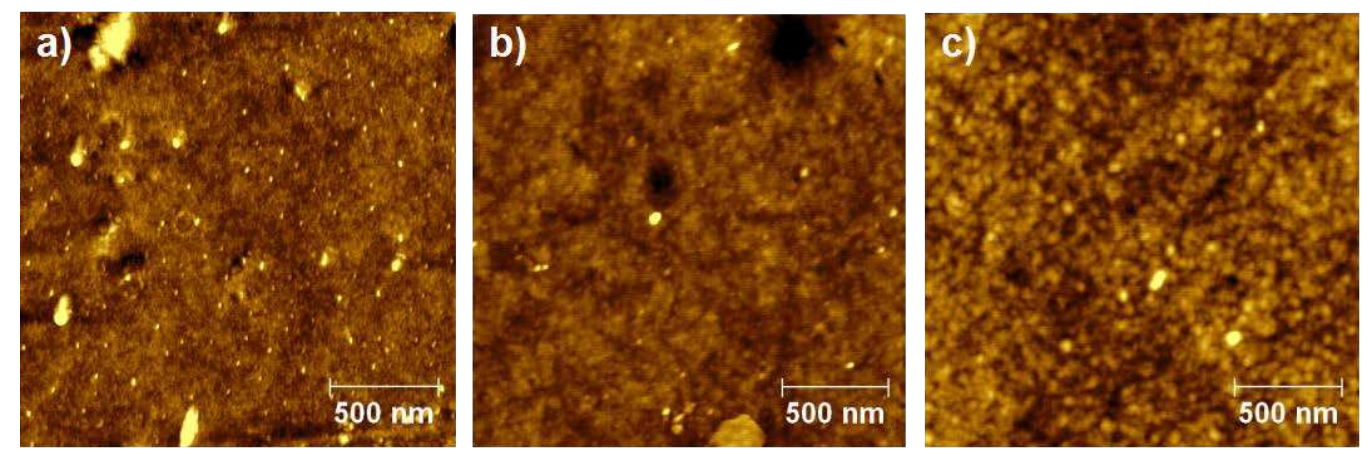

Figure 2. IC-AFM height images $(2 \mu \mathrm{m} \times 2 \mu \mathrm{m})$ of (a) PVC, (b) PVC-NCS and (c) PVCLam822, acquired in intermittent contact mode. The height scale was $10 \mathrm{~nm}$ for the 3 images.

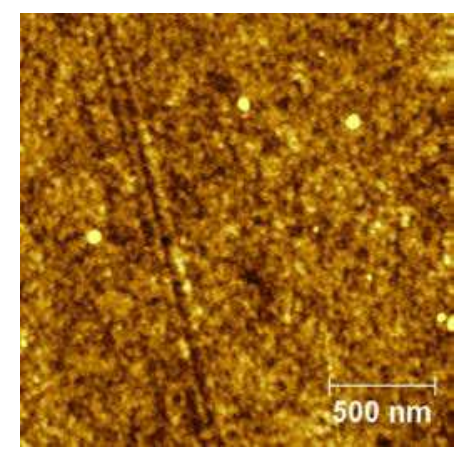

